\title{
Analytical Hierarchy Process for Natural Fiber Composites Automotive Armrest Thermoset Matrix Selection
}

\author{
M.U Rosli ${ }^{1,}{ }^{*}$, Mohd Riduan Jamalludin ${ }^{1}$, C.Y. Khor ${ }^{1}$, Muhammad Ikman Ishak $^{1}$, H. Jahidi ${ }^{1}$, \\ Norsyahadah Yeop Wasir ${ }^{1}$, Wan Mohd Faizal $^{1}$, Wan Nur A'tiqah Wan Draman ${ }^{1}$, Lailina $\mathrm{NM}^{1}$, Ras \\ Izzati Ismail $^{1}$ \\ ${ }^{1}$ Faculty of Engineering Technology, Universiti Malaysia Perlis (UniMAP), Level 1, Block S2, \\ UniCITI Alam Campus, Sungai Chuchuh, 02100, Padang Besar, Perlis, Malaysia.
}

\begin{abstract}
The automotive industry is currently shifting to a 'green' outlook since that the popularity of natural fibers in composites plastics is accelerating in many areas and particularly the automotive industry. Nowadays, consumers are looking for vehicles more environmentally friendly and lighter in weight. For this reason, the engineers are now focusing to substitute the metal parts on utilizing the natural fiber composites. Selecting the right material in product development is a crucial decision. Imprecise decision can cause the product to be remanufactured and not in optimized condition. One of the methods that can be employed is Analytical Hierarchy Process (AHP). This paper illustrates the implementation of AHP method in order to select the most appropriate thermoset matrix for natural fiber composites automotive armrest. The selection is based on the weight reduction as the major aim of the study.
\end{abstract}

\section{Introduction}

In general, armrests are also found on chairs. In an automotive context especially in most modern and comfortable cars, an armrest is a function that provides the passengers a place to rest their arms. A wide armrest located between the back seats is part of interior design nowadays, if the central seating area is not in use, it can be folded out. Usually, armrests may be also equipped with other accessories such as cup holders and storage compartments. Some vehicles also offer the spot for controlller such as air-conditioner controls audio or window motors. Armrest also built into the door of the car, often forming part of the door pulling handle. Occasionally, one or two armrests may also be attached to each individual seat such as in MPVs and SUVs [1].

An armrest with a cup holder of a car as shown is Figure 1 which located at the back seat. In most design, bounded by soft polyurethane foam with an outer leather layer, the armrest has a steel frame inside [2]. The frame of the armrest is usually made by forming sheet metal which is formerly made by $2-\mathrm{mm}$-thick sheet metal which used to carry the load

*Corresponding author: uzair_rosli@yahoo.com.my 
make it as the most vital part need to be focused. The steel frame should be replaced with plastics or composite materials due to the heavy weight and high manufacturing cost including punching, stamping and welding processes. By substituting with new material, the product's weight will be reduced as well as increase the production by the application of the injection molding manufacturing process.

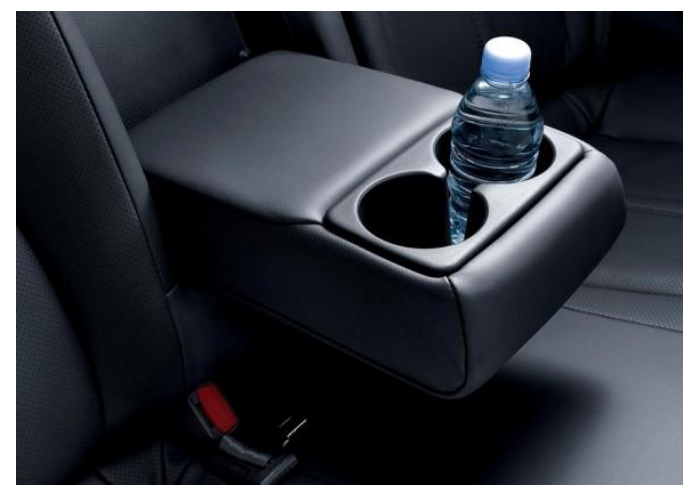

Fig. 1. Armrest serves a cup holder function [3]

\section{Material}

Over the years, in European countries, the car manufacturers and suppliers for headliners, dashboards seat backs, door panels, and interior parts have been applied natural-fiber composites with thermoplastic and thermoset matrices widely [4]. The utilization of weight reduction, low cost natural fibers such as hemp, kenaf, jute, sisal, and flax put forward such advantages in return such as reductions in weight, cost and recyclability in various automotive interior and exterior parts. The manufacturing of natural-fiber composites consists of the use of either a thermoset or thermoplastic polymer binder system combined with the natural-fiber preform or mat. In applications of automotive industry, Polyester, Vinylester, and Epoxy resins are the key thermoset resins used in natural-fiber composites. Thermoset properties data is displayed in Table 1.

Table 1. Properties of Thermoset Polymers [4]

\begin{tabular}{|l|c|c|c|}
\hline Property & $\begin{array}{c}\text { Polyester } \\
\text { resin }\end{array}$ & $\begin{array}{c}\text { Vinylester } \\
\text { resin }\end{array}$ & Epoxy \\
\hline Density (g/cc) & $1.2-1.5$ & $1.2-1.4$ & $1.1-1.4$ \\
\hline Tensile strength (MPa) & $40-90$ & $69-83$ & $35-100$ \\
\hline Elastic modulus (GPa) & $2-4.5$ & $3.1-3.8$ & $3-6$ \\
\hline Compressive strength (MPa) & $90-250$ & 100 & $100-200$ \\
\hline Elongation (\%) & 2 & $4-7$ & $1-6$ \\
\hline Cure shrinkage (\%) & $4-8$ & - & $1-2$ \\
\hline Izod Impact Notched (J/cm) & $0.15-3.2$ & 2.5 & 0.3 \\
\hline Water absorption (24h @ 20 c) & $0.1-0.3$ & 0.1 & $0.1-0.4$ \\
\hline Cost (RM/KG) [5] & $4.63-$ & $9.26-$ & $13.89-$ \\
& $9.26 / \mathrm{kg}$ & $18.52 / \mathrm{kg}$ & $69.45 / \mathrm{kg}$ \\
\hline
\end{tabular}

In this paper, the material selection of thermoset matrix for natural fiber composites automotive armrest using Analytical Hierarchy Process (AHP) method is presented in results and discussion. 


\section{Results and discussion}

Expert Choice software was utilized to select the most appropriate thermoset polymer between Polyester resin, Vinylester resin and Epoxy as depicted in Figure 2. Since that the aim was the weight and cost reduction, the property of density and cost was weighted as $18.6 \%$ or 0.186 . The strength property including Elastic Modulus, Tensile Strength, Compressive Strength, Elongation, Izod impact and cure shrinkage was in second priority in this study with $9.6 \%$ or 0.096 and the least priority for water absorption with $5.7 \%$ or 0.057 .

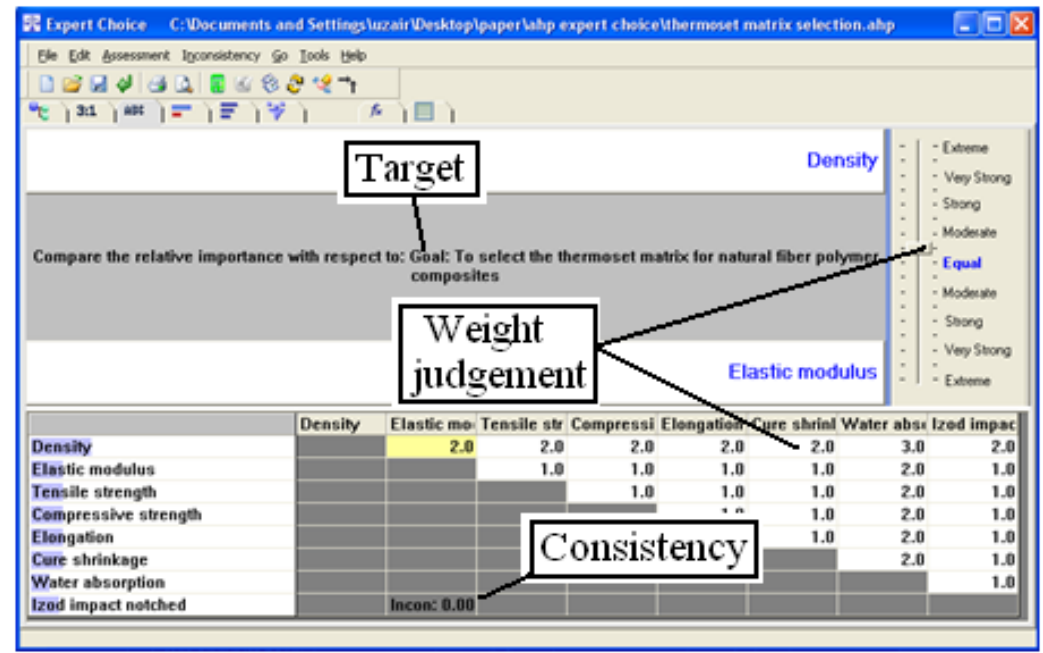

Fig. 2. Expert Choice software of AHP method

Figure 3 showed the result of each thermoset polymer alternatives with respect to each property. The weight for each alternative during the pair-wise comparison was based on the data in Table 1. The consistency analysis of the pair-wise was in best condition since the data came in numerical.

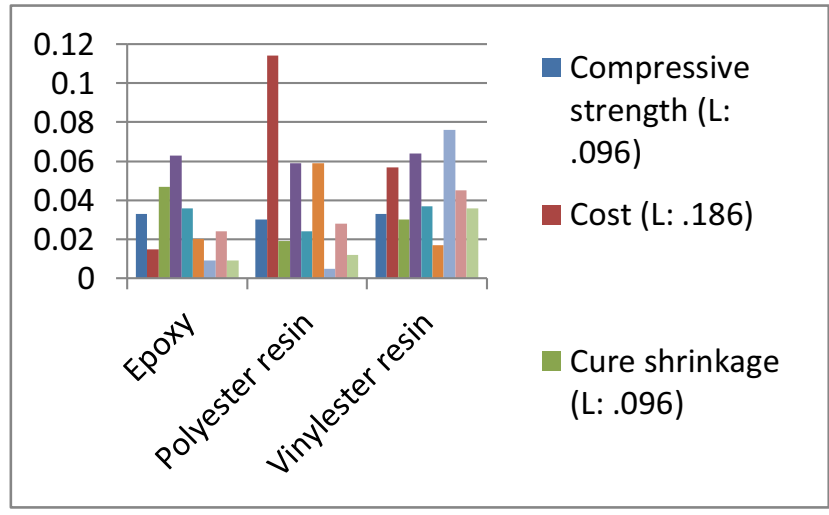

Fig. 3. Weight of each property and the thermoset alternatives

In the end result of the alternatives ranking, the Vinylester resin had the highest value (0.394 or $39.4 \%)$ among the other thermoset materials. The second highest was Polyester 
with $(0.350$ or $35.0 \%)$ and the lowest value or the last choice was Epoxy resin with only $0.256(25.6 \%)$. Vinylester resin was preferred since it had the highest value among three alternatives.

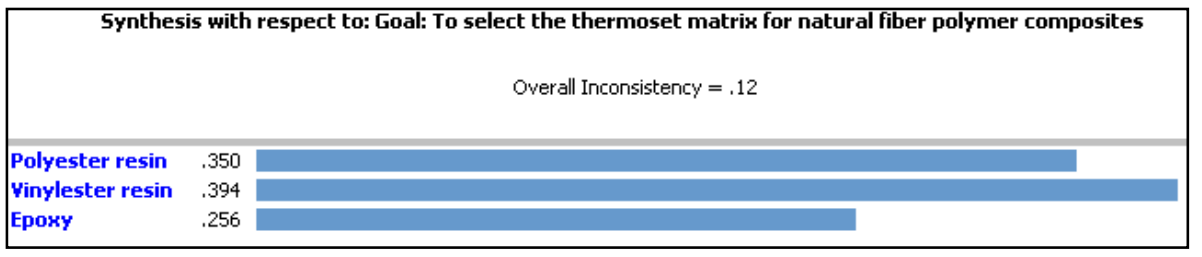

Fig. 4. Result of selection

As a new comer in the thermosetting resins family, Vinylester was a resin which usually formed by the result of reaction between epoxy resin and an ethylenically unsaturated monocarboxylic acid, with regularly used acids such as methacrylic and acrylic acid. The reaction product was then dissolved in a reactive solvent, such as styrene, to 35 - 45 percent content by weight [6]. Vinylester resins unite good thermal, excellent chemical resistance as well as mechanical properties, easeness of processes and quick cure characteristics of polyester resins. Compared with epoxies, Vinylester resin had enhanced moisture resistance when cured at room temperature. Despite of the similarity in their molecular structure to polyesters, however it differ in that the reactive sites were placed at the ends of the molecular chains which in position to absorb energy which results in a stronger material compared to polyesters [4].

\section{Conclusions}

As conclusion, in this study case of thermoset selection for natural fiber composites automotive armrest by the major aim of cost and weight reduction, Vinylester resin was discovered as the most appropriate material by implementing the AHP selection method. AHP could aid to evaluate the data and select the best alternative based on the criteria aspects of the decision. Application of AHP for material selection could improve the product's quality and product development process would be shortened.

The research was conducted under Fundamental Research Grant Scheme through project number 0301-12-1108FR. The authors thank to Mr. Zaraq Shaifuddin Zamrah, Section Manager of Vendor Improvement and Education in Proton Automobile Company (Proton Sdn. Bhd) for providing the information and guidance in this research work.

\section{References}

1. R. Lueder, P. Allie, Ergonomics Review: Armrest Design and Use. An Ergonomics Review of the Literature for Steelcase Furniture (1997)

2. H.S. Park, X.P. Dang, Int. J. Automot. Techn., 12, 83 (2011)

3. Information on http://nazakia.primuscore.com/category/sections/minivanssuvs/all-newsportage

4. James Holbery, Dan Houston, Jom-Us, 58 (11), 80 (2006)

5. A. Brismarck, S. Mishra, T. Lampke, Natural fibres,Biopolymers and Biocomposites, 37, (2005)

6. D. Ray, B.K. Sarkar, A.K. Rana, N.R. Bose, Compos. Part A-Appl. S, 32, 119 (2001) 